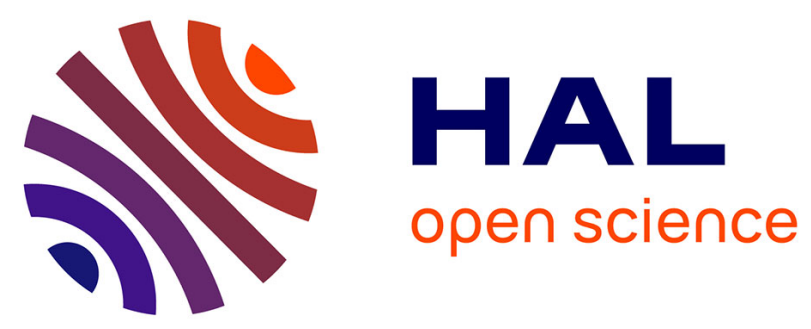

\title{
Thermoelastic imaging using optical interferometer : sensitivity optimization and super-resolution
}

\author{
B. Cretin, O. Franquet, E. Farnault, D. Hauden, J. Lesne
}

\section{To cite this version:}

B. Cretin, O. Franquet, E. Farnault, D. Hauden, J. Lesne. Thermoelastic imaging using optical interferometer: sensitivity optimization and super-resolution. Journal de Physique IV Proceedings, 1994, 04 (C7), pp.C7-7-C7-10. 10.1051/jp4:1994702 . jpa-00253143

HAL Id: jpa-00253143

https://hal.science/jpa-00253143

Submitted on 1 Jan 1994

HAL is a multi-disciplinary open access archive for the deposit and dissemination of scientific research documents, whether they are published or not. The documents may come from teaching and research institutions in France or abroad, or from public or private research centers.
L'archive ouverte pluridisciplinaire HAL, est destinée au dépôt et à la diffusion de documents scientifiques de niveau recherche, publiés ou non, émanant des établissements d'enseignement et de recherche français ou étrangers, des laboratoires publics ou privés. 


\title{
Thermoelastic imaging using optical interferometer: sensitivity optimization and super-resolution
}

\author{
B. Cretin, O. Franquet, E. Farnault, D. Hauden and J.L. Lesne* \\ Laboratoire de Physique et Métrologie des Oscillateurs du CNRS, associé à l'Université de \\ Franche-Comté-Besançon, 32 avenue de l'Observatoire, 25044 Besançon cedex, France \\ * Electricité de France, Direction des Etudes et Recherches, 25 allée Privée, Carrefour Pleyel, \\ 93206 Saint-Denis, France
}

\begin{abstract}
The noncontacting thermoelastic microscope is based on $\mathrm{Ar}^{+}$laser excitation and optical probe detection. The main problem is to adjust the experimental parameters for sensitivity optimisation. This paper points out that 3-D model predicts the sample thermoelastic behaviour. Calculated criteria enable the choice of the best values of parameters. Experimental results show the advantage of an imaging criterion : particularly contrast of metallic sample images is related to the relative position of excitation and detection beams.
\end{abstract}

\section{1 - Introduction}

Thermoelastic imaging allows the detection of variations of thermal or/and elastic properties close to the surface of solid samples. Many authors have shown that image contrast is related to elastic anisotropy [1, 2]. Our thermoelastic microscope [3] provides thermal waves (photoreflectance) and thermoelastic images. So different contributions are discernible. Experimentally, high-contrast images are obtainable only in some range of the parameters values. A 3-D model has been developed to clarify the choice between the different operating parameters. In this article, we underline that a theoretical criterion can be used to optimise the contrast of image when thermal inhomogeneities are observed and when a high resolution is required. Experimental results point out that particular values enhance phase image contrast. Moreover, a theoretical interpretation and applications of super-resolution are presented.

\section{2 - 3-D model for thermoelastic displacements}

Theoretical treatment of photoacoustically generated acoustic waves is a complex problem that has not been completely solved. Nevertheless many authors have given theoretical solutions in particular cases [4 8]. In reflection mode, measured displacements are close to the thermoelastic source if excitation and detection beams are focused with the same lens. Thus at low frequencies, elastic propagation solutions can be neglected and the main contribution is "photodisplacement".

The developed model is based on a Hankel transform that is a useful mathematical tool for polar coordinate calculations. Analytical results have been already published [9].

A comparison between theoretical and experimental values of the normal displacement close to the excitation area (normal displacement is measured with an asymmetrical heterodyne laser probe [10]) is shown in Fig. 1. Adjusted parameters are sample reflectivity, beam radii and acousto-optic modulator delay. 


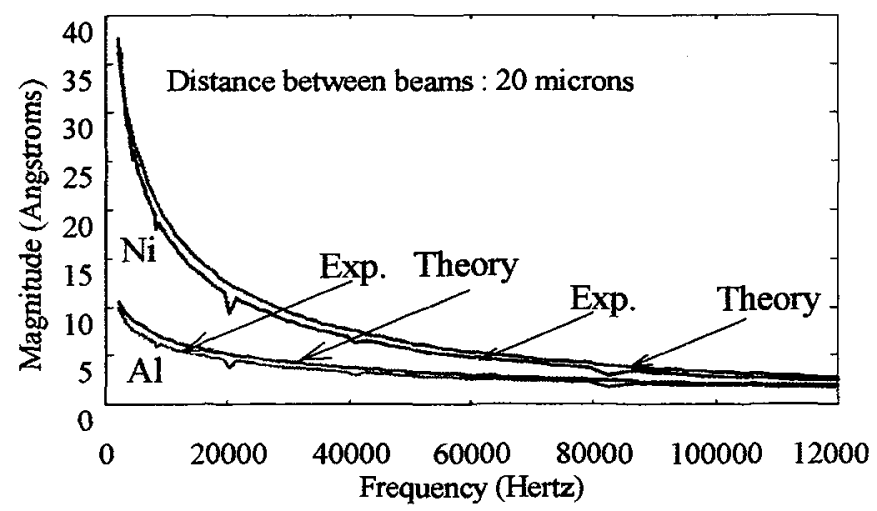

Fig. 1 : Theoretical and experimental thermoelastic displacements versus frequency

\section{3 - Model predictions}

It is well known that lateral resolution and investigation depth are essentially related to the excitation beam diameter $w$ [11] when $w$ " $\mu_{T}\left(\mu_{T}\right.$ thermal penetration depth). This feature is also found in other near-field microscopes when the source diameter is smaller than the investigation wavelength [12]. Our 3-D model gives the $u_{z}(0) / e$ isolevel and shows the $1 / \mathrm{e}$ heated volume. For a $1 \mu \mathrm{m}<\mathrm{w}<30 \mu \mathrm{m}$ and low frequency excitation, the calculated volume shape (Fig. 2) points out that the apparent penetration depth is $\sim \mathrm{w}$ for the Al sample. In this super-resolution mode, the lateral resolution is $\sim \mathrm{w}$ and is not very sensitive to variations of the excitation frequency.

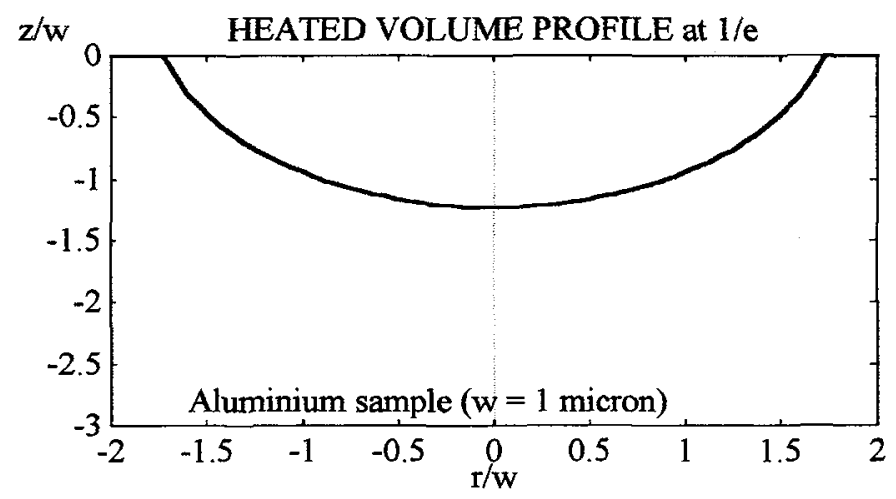

Fig. 2 : Calculated 1/e volume for Al sample $(f=10 \mathrm{kHz})$

Experimental verification of super-resolution is given in Fig. 3. The sample is made of stainless steel. Both phase images have been obtained at the same frequency $(50 \mathrm{kHz})$. Figure $3 \mathrm{a}$ shows the image when beams are focused with a $\times 20$; N.A. 0.40 ULWD microscope objective. The $514 \mathrm{~nm}$ wavelength beam radius is estimated $\sim 2.5 \mu \mathrm{m}$. Figure $3 \mathrm{~b}$ is an image of the same area with $\mathrm{a} \times 80$ objective (estimated radius $\sim .7 \mu$ $\mathrm{m}$. Grain contrast has disappeared due to the low penetration depth (surface hammering). 


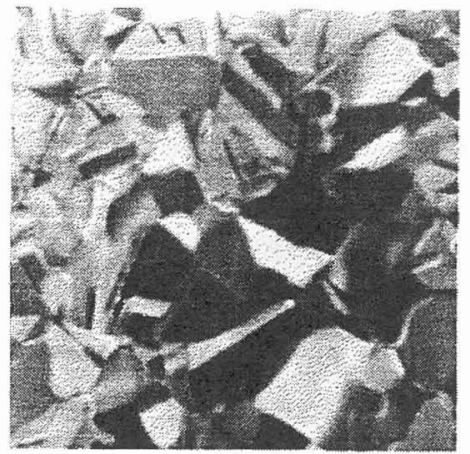

3 a
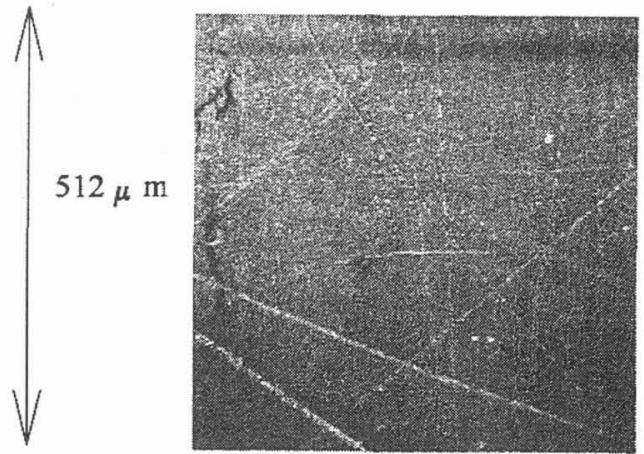

$3 \mathrm{~b}$

Fig. 3 : Super-resolution : experimental verification on a stainless steel sample a : $\times 20$, N.A. 0.40 ULWD objective, b : same area, $\times 80$, N.A. 0.75 objective

The model also predicts experimental parameters which act on the images contrast. Optimisation of the parameter values can be obtained by different criteria that depend on applications. For example, the required features for thermoelastic imaging optimisation could be :

- high lateral resolution (small investigated volume)

- high amplitude and phase sensitivities to thermal diffusivity variations

- good signal to noise ratio.

Corresponding imaging criterion can be written:

$$
C_{i m}=\frac{\Delta \phi}{\frac{\Delta \alpha}{\alpha}} \times \frac{\frac{\Delta A}{\Delta \alpha}}{\frac{\Delta \alpha}{\alpha}} \times A \times \frac{1}{V_{\text {heat }}}
$$

where $\Delta \phi$ is the phase variation due to $\Delta \alpha, \alpha$ the thermal diffusivity, $\mathrm{A}$ the displacement amplitude and $V_{\text {heat }}$ the heated volume.

$C_{i m}$ has been calculated (Fig. 4) versus a dimensionless parameter $\mathrm{r} / \mathrm{w}$ (distance between excitation and detection beams) and $\sqrt{ } f\left(f_{\mathrm{o}}\left(f\right.\right.$ : excitation frequency and $f_{\mathrm{o}}=\mathrm{a} / \pi \mathrm{w}^{2}$ is 1-D to 3-D transition value). We have noted the calculated shape is quasi-identical for 1 to $100 \mu \mathrm{m}$ w range.

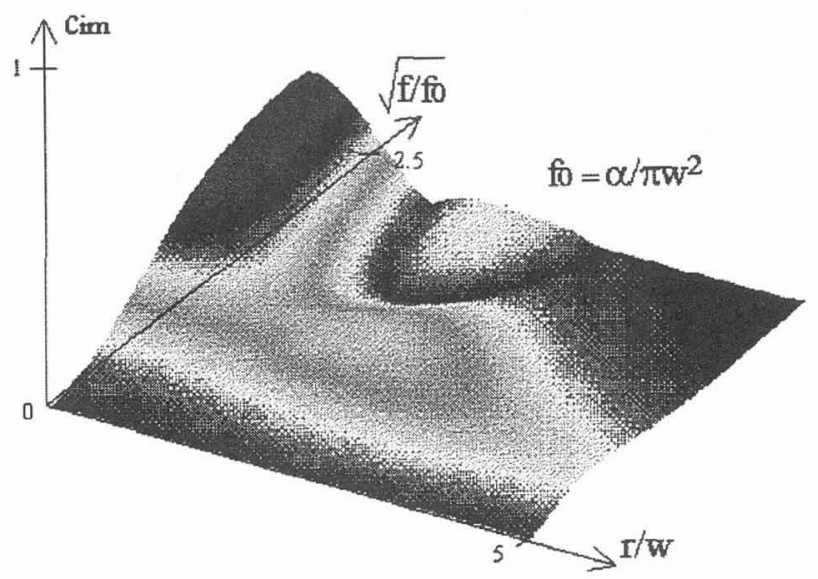

Fig. 4 : Calculated values of the imaging criterion $C_{i m}$ 
Maxima values of $C_{i m}$ lead to the choice of optimum parameters. Best signal to noise ratio is obtained for $r=0$ (superimposition of excitation and detection beams), but in that case, phase contrast is the lowest. Optimal parameters values are $f_{\text {opt }}=224 \mathrm{kHz}, \mathrm{r}_{\text {opt }}=15 \mu \mathrm{m}$. Figure 5 shows phase images for optimal value of $f$. In Fig. 5a, $r=0$ and the image does not reveal subsurface structure. Figure $5 \mathrm{~b}$ is a phase image of the same area. Optically estimated distance between excitation and detection beams has been adjusted to $r_{\text {opt }}$. A high phase contrast is observed and demonstrates the interest of using the criterion $C_{i m r}$
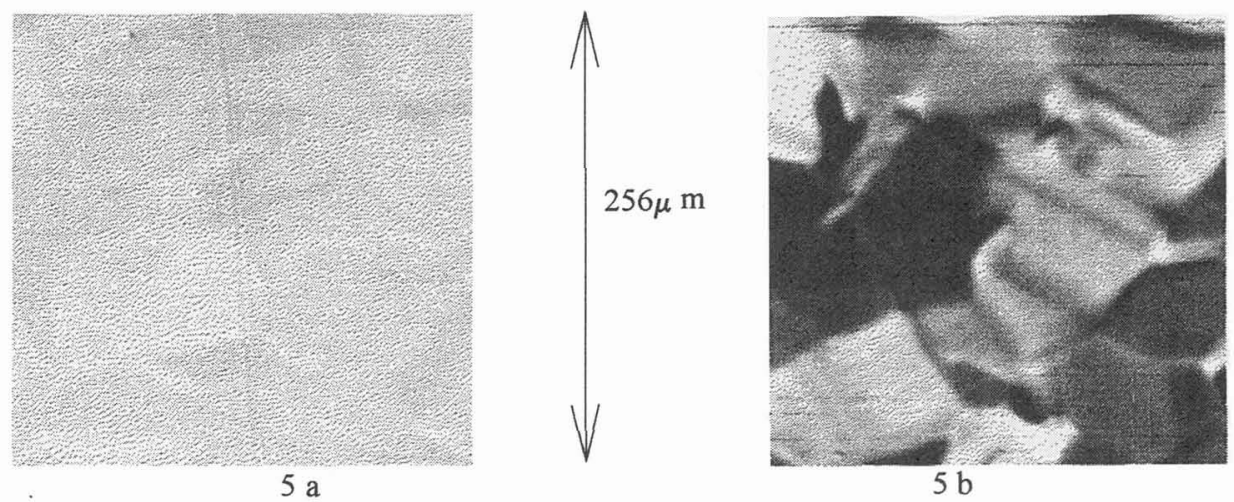

Fig. 5 : Phase image contrast versus excitation and detection beams distance $r$

$a: r=0$; phase contrast is negligible

$\mathrm{b}: \mathrm{r}=\mathrm{r}_{\mathrm{opt}} ;$ high phase contrast showing granular structure

\section{4 - Conclusion}

In most applications of that NDE method (metallurgy, power plant inspection, aeronautics, etc.), the right choice of the parameter is important for the expertise. We have shown 3-D model, even limited to isotropic and homogeneous sample, gives optimised values of the parameters. These values are deduced from maxima of the defined criteria depending on aimed applications. Especially, contrast of phase image is very sensitive to distance between excitation and probe beams. If they are superimposed, no phase information is available.

\section{References}

[1] Cargill G.S., in Scanned Image Microscopy, ed. by E.A. Ash (Academic Press, London 1980), pp. 319-330.

[2] Maclachan J.W., Murphy J.C., in "Photoacoustic and Photothermal Phenomena" (edited by P. Hess and J. Peizl, vol. 58, Springer Verlag, 1988) pp. 294-297.

[3] Cretin B., Takadoum J., Mahmoud A., Hauden D., Thin Solid Films 209,(1992) 127-131.

[4] Rosencwaig A., Gersho A., Journal of Appl. Phys. 47 (1) (1976) 64-69.

[5] Jackson W., Amer N.M., J. Appl. Phys. 51 (6) (1980) 3343-3353.

Rousset G., Lepoutre F., Bertrand L., J. Appl. Phys. 54 (5) (1983) 2383-2391

[7] Rose L.R.F., J. Acoust. Soc. Amer. 75 (1984) 723-732.

[8] Wetsel G.C., IEEE Trans. on Ultrasonics, Ferroelectrics and Frequency Control UFFC-33 (5) (1986) 450-461.

[9] Cretin B., 4th Course of the International School of Physical Acoustics (A. Alippi, Ed., World Scientific Publishing, 1992), p. 197.

[10] Royer D., Dieulesaint E., Martin Y., Ultrasonics Symp. Proc., IEEE cat. n85CH2209-5 (ed. B.R. McAvoy, 1985), p. 432.

[11] Inglehart L.J., Lin M.J., Favro L.D., Kuo P.K., and Thomas R.L., Ultrasonics Symp. Proc., IEEE cat. 83CH1947-1 (ed. B.R. McAvoy, 1983), pp. 668-671.

[12] Cretin B., Sthal F., Appl. Phys. Lett. 62 (8) (1993) 829-831. 